\title{
The Mouse as a Model for Age-Related Hearing Loss - A Mini-Review
}

\author{
Michael R. Bowl ${ }^{\mathrm{a}}$ Sally J. Dawson ${ }^{\mathrm{b}}$ \\ a Mammalian Genetics Unit, MRC Harwell, Harwell Oxford, and ${ }^{\mathrm{b}}$ UCL Ear Institute, London, UK
}

\section{Key Words}

Age-related hearing loss · Genetics · Mouse model ·

Presbycusis · Sensory loss

\begin{abstract}
The most common form of sensory disability is age-related hearing loss (ARHL), also referred to as presbycusis. ARHL is a complex disorder with a mixture of genetic and environmental components, a combination that leads to a progressive decline in hearing function with increased age. In the last 15 years, there has been a vast increase in our knowledge of the genes that underlie congenital deafness and the critical components of hearing. In contrast, knowledge of the pathological processes involved in ARHL remains very limited. The mouse has proved an essential tool in the identification of early-onset deafness genes and in revealing the basic mechanisms of hearing. As focus is now turning toward elucidating the most common form of hearing loss, ARHL, the mouse will again play a fundamental role in this research. Here, we review the need for an animal model and discuss the suitability of the mouse as an ARHL model. Finally, we outline the ways in which hearing researchers are utilising the mouse in the investigation of ARHL and provide perspectives on the need for these data to be integrated with the results of human genetic studies.

(c) 2014 S. Karger AG, Basel
\end{abstract}

\section{Introduction}

An age-dependent, progressive decline in hearing function is so common that it is often mistakenly perceived as an inevitable part of the ageing process in humans. It is partly as a consequence of this perception that the overall contribution of hearing loss to disability and reduced quality of life is under-appreciated. However, in the context of increasing longevity of the population, the contribution of hearing loss to the general health and well-being of individuals during that extended lifespan is of great clinical and economic significance [1]. Age-related hearing loss (ARHL) is the most common sensory loss in the elderly. The frequency of bilateral hearing loss doubles for every 10 years over the age of 50 . Thus, $15 \%$ of people between 50 and 59 years have bilateral hearing loss, rising to $31 \%$ in people $60-69$ years of age and $63 \%$ in those over 70 years (US National Health and Nutrition Examination Survey [2]). Projections in both the US and UK suggest that the number of people affected by ARHL will effectively double by 2031, largely due to an increased lifespan [2] (Action on Hearing Loss http://www.action onhearingloss.org.uk/your-hearing/about-deafnessand-hearing-loss/statistics.aspx). ARHLinevitably causes communication difficulties and is associated with social isolation, depression and reduced physical and cognitive

\section{KARGER 125}

(c) 2014 S. Karger AG, Basel

0304-324X/14/0612-0149\$39.50/0

E-Mail karger@karger.com

www.karger.com/ger 
function $[3,4]$. There is a growing literature on the association between hearing loss and cognitive decline; however, it is unknown whether this link is via common pathological mechanisms or because the lack of auditory input contributes to accelerated cognitive decline [5]. Hearing aids are currently the only treatment option for ARHL. In this context, research into the causes and pathology that underlie ARHL is greatly needed in order to develop therapeutic strategies and treatments.

\section{The Need for an Animal Model}

Research to reveal the causes of ARHL faces a number of significant challenges. First, the auditory system is highly complex. An indication of the high number of critical components in this sensory organ is shown by the number of genes in which mutations can cause congenital deafness; over 150 genetic loci have been mapped, and it is likely that ARHL will be at least as heterogeneous, if not more so [6] In order to detect and discriminate among sound levels across a range of frequencies, the auditory system has a sophisticated, tonotopic organisation that needs to be maintained from the cochlea to the brain. There are 26 different cell types just within the cochlea, each with a specialised function and arranged into an intricate and highly organised structure (fig. 1a-c). Within this structure, there are the mechanical transducers, the sensory hair cells. Progressive loss of these cells throughout life is associated with ARHL, typically beginning in the higher frequencies due to loss of hair cells in the basal turn of the cochlea and later progressing to the apical turn, affecting lower frequencies. However, it is still unclear whether this hair cell loss is the underlying cause of ARHL or is a result of pathology that originates elsewhere in the auditory system and eventually leads to hair cell death. Schuknecht's seminal work on the pathology of ARHL, beginning in the 1950s, proposed four pathological subtypes in presbycusis: sensory, involving hair cell loss (fig. 1d); strial (or metabolic), involving degeneration of the stria vascularis and reduction in endocochlear potential; neural, involving loss of spiral ganglion neurons (SGNs; fig. 1e), and mechanical, involving stiffening of the basement membrane, although the latter is now thought to be a manifestation of strial presbycusis [7-9]. Evidence suggests a mixed pathology of these different subtypes is present in most people with ARHL, indicating that a number of different pathways contribute to the hearing loss $[8,9]$.

In addition to the complexity of the system, any biochemical analysis of the cochlea is compromised because removal of intact human cochlear tissue for functional characterisation, even post-mortem, is confounded by the cochlea being embedded within the temporal bone, the hardest bone in the body. In this scenario, a genetic approach is often deployed because it does not rely on biological knowledge or access to affected tissue. However, as with other highly heterogeneous and complex disorders, genome-wide association (GWA) studies into adult hearing function have had very limited success in identifying ARHL susceptibility genes. To date, five GWA studies have been performed and none has identified a genetic association above the level of statistical significance sufficient for such genome-wide studies. Nevertheless, these studies do provide a valuable candidate gene list for further investigation. The first GWA study into ARHL by Friedman et al. [10] reported an association between single nucleotide polymorphisms within the GRM7 gene and ARHL, which - although not above genome wide significance - was replicated in some cohorts, an important criterion in validating genetic associations. The second by Van Laer et al. [11], employing samples from the isolated Finnish Saami population, revealed no significant GWAs for ARHL. The third by Girotto et al. [12] utilised a metaanalysis approach to study normal hearing traits in adults, employing samples from 6 isolated European populations. This study detected 8 suggestive loci in genes expressed in the inner ear, including DCLK1, PTPRD, CMIP and GRM8 (a homologue of GRM7), as well as loci containing genes of unknown function or genes whose function has not been linked to hearing. The fourth GWA study was undertaken into the hearing status of 3,614 individuals (all aged 44-45 years) in the British 1958 Birth Cohort and again failed to find a significant association but provided the basis for the subsequent characterisation of a novel hearing gene, ESRRG, in a knock-out mouse model [13]. The fifth by Fransen et al. [14] is an extension of the first GWA study, employing a larger sample set. This recent study revealed no significant GWAs for ARHL and also did not add support to any of the previously reported associations in GRM7 or GRM8. Despite these disappointing outcomes, it is likely that these studies will provide a valuable candidate gene set for deciphering the molecular mechanisms that can cause ARHL, but they require secondary validation through functional assessment for a role in hearing loss $[10,12,13]$. In summary, the biologist, cell physiologist and geneticist all face particular challenges in human ARHL research, meaning the need for animal models to help identify and characterise ARHL genes, and to corroborate genetic findings in humans is of utmost importance. 


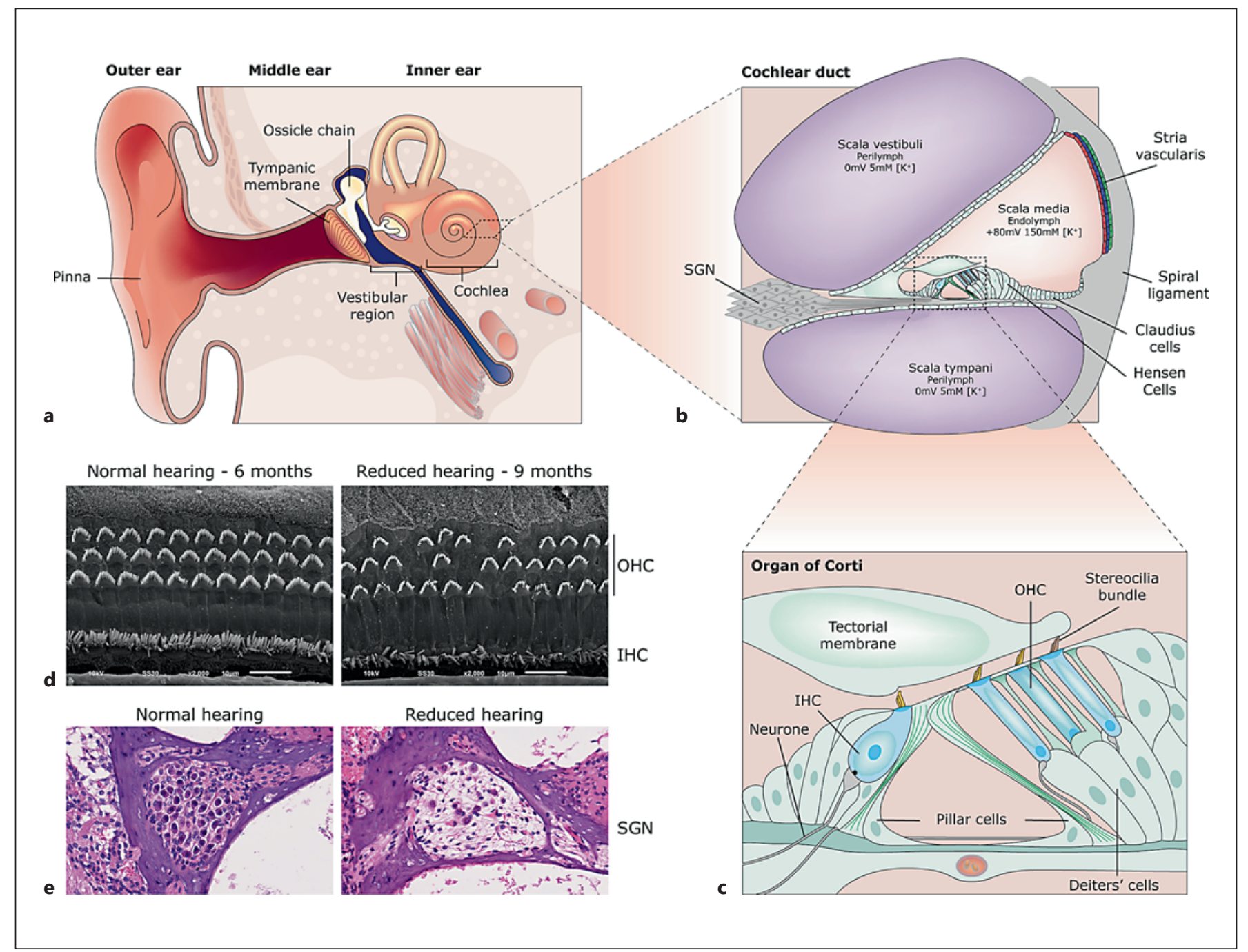

Fig. 1. The mammalian ear. a Sound is collected by the outer ear and funnelled to the tympanic membrane, which vibrates and causes the ossicular bones of the middle ear to articulate. This transfers the energy of the sound wave to the oval window of the fluid-filled cochlea in the inner ear. b Cross section through the cochlea shows the cochlear duct, which is divided into three compartments, the scala vestibuli, scala media and scala tympani. Scala vestibuli and scala tympani contain perilymph, whereas the scala media contains a fluid called endolymph. Endolymph has a composition that is high in potassium and low in sodium, with a positive voltage of $80-100 \mathrm{mV}$, which is generated and maintained by the stria vascularis. c The endolymph bathes the apical surface of the sensory inner and outer hair cells of the organ of Corti. These sensory cells have actin-filled stereocilium bundles projecting from their surface toward the tectorial membrane. Deflection of the bundle leads to opening of mechanically gated transduction channels, which results in depolarisation of the hair cell and ultimately exocytosis of glutamate-containing vesicles at the basolateral presynaptic membrane. The neurotransmitter diffuses across the synaptic cleft to the postsynaptic membrane of SGN to elicit an action potential. The structure and function of the inner ear are similar in humans and mice. $\mathbf{d}$ Scanning electron micrographs of cochlear sensory epithelia showing progressive loss of outer hair cells between 6 and 9 months of age in the trombone mouse model of late-onset hearing impairment [Bowl, unpubl. data]. e Histological sections from the melody mouse model of early-onset hearing loss showing loss of SGNs at 2 months of age when compared to a normal-hearing littermate. IHC = Inner hair cell; $\mathrm{OHC}=$ outer hair cell. Adapted with permission from Macmillan Publishers Ltd: Nature Reviews Genetics [15], copyright (2008). 


\section{The Mouse as a Model for Hearing}

Mice continue to be the predominant model organism for hearing research. Similarities in the auditory structure and physiology between mice and humans, the close evolutionary relationship of genomes ( $\sim 99 \%$ of genes in mice have a human orthologue), relatively low housing costs (small size, short lifespan), genetic standardisation and the available genetic toolkit together make the mouse a useful and crucial model system for studying the functional genomics of the auditory system [15-17]. The ease at which mice can be genetically manipulated has led to the generation of numerous mouse models that mimic human hearing loss mutations, allowing the study of gene function. Additionally, the ability to screen large numbers of mice for hearing defects by means of a simple click box test meant that the hearing field was an early adopter of mutant mouse technology. Hence, in addition to gene-driven approaches, phenotype-driven screens of chemically induced mouse mutants have led to the identification of many novel deafness genes, which have subsequently helped to increase our knowledge and understanding of the genetic bases of human hearing impairment $[15,16,18]$. Critically, characterisation of these mouse models has allowed the relationship between genetic variants and their consequent structural and pathological changes within the ear to be explored, something that is rarely possible in humans. The highthroughput phenotyping of spontaneous, genetic and chemical-induced mutants for hearing loss, and the subsequent mapping and identification of the mutated genes has provided the basis for our current understanding of the key players in the auditory system. This phenotype-driven paradigm, which has proven so successful in mapping hearing genes, has also been implemented for the discovery of disease genes in other disciplines [19].

\section{Insights into ARHL Pathology from Mouse Inbred Strains}

Animal models are commonly used to investigate the genetic and physiological basis of ageing and age-related disease. They are required because the study of ageing in humans is complicated by several factors, including longevity, accumulated environmental influences, genetic heterogeneity and ethical issues. In particular, the laboratory mouse has become a very robust and reliable tool for ageing research, not least because of the ability to strictly control both intrinsic and extrinsic factors, e.g. genetic background, diet, environment and health status [20]. In addition, the mouse is a practicable and useful model because they have a short lifespan, meaning the effects of age are apparent within a contracted time period, and tissues can be obtained and analyzed at all stages of the ageing process [21].

As previously mentioned, mouse mutants have been instrumental in the discovery of genes that are involved in congenital and early-onset hearing loss. However, utilisation of the mouse for the study of ARHL has mainly focused on inbred strains, as it has long been known that certain strains exhibit very different ageing characteristics [22]. In addition, certain inbred strains display an innate propensity to noise-induced hearing loss $[23,24]$. These strain-specific traits indicate a genetic basis for these differences, and consequently inbred mice have been used to elucidate genetic loci and pathology associated with ARHL and noise-induced hearing loss (table 1). To date, almost 20 loci contributing to ARHL have been defined (hearingimpairment.jax.org/table1.html). However, the underlying genes have been identified for only four of these ARHL ( $a h l$ loci, and they are Cdh23 (ahl1), Cs (ahl4), Gipc3 (ahl5) and Fscn2 (ahl8) [25-28]. Interestingly, three out of four of the identified genes (Cdh23, Gipc3 and Fscn2) encode proteins that are reported to be important for hair cell stereocilium structure and/or function (table 1). This reinforces Schuknecht's premise that defects in these sensory cells contribute to presbycusis. The $C d h 23^{\text {ahl }}$ allele is defined by the presence of an A rather than a $\mathrm{G}$ at the last position of the 7 th coding exon. This hypomorphic allele causes an increased frequency of in-frame exon skipping and is common to at least 10 inbred strains with increased susceptibility to ARHL [22]. Cdh23 encodes a cell-cell adhesion glycoprotein expressed in the sensory epithelium of the inner ear and is required for stereocilium bundle formation and function. Mutant alleles of the human orthologue $\mathrm{CDH} 23$ cause recessive deafness (DFNB12) and Usher's syndrome (USH1D). The widely used and much studied C57BL/6J inbred strain has the $C d h 23^{\text {ahl }}$ allele [22]. This strain begins to display elevated hearing thresholds from as early as 3-6 months of age, starting in the high frequencies, then the low, before leading to a profound hearing loss across all frequencies. Given the expression pattern observed for this protein, it is unsurprising that hearing loss is associated with hair cell degeneration, a feature of sensory ARHL. This includes progressive loss of both inner and outer hair cells in an age-dependent manner proceeding from the base to the apex of the cochlear spiral, with outer hair cell loss observed at the base of the cochlea by 3 months of age [29]. Between 3 and 7 months of age, 
Table 1. Mouse models of ARHL

\begin{tabular}{|c|c|c|c|c|c|}
\hline Locus & Gene & Protein & Function $^{\mathrm{a}}$ & Human $\mathrm{HL}^{\mathrm{b}}$ & Reference \\
\hline Ahl1 & Cdh23 & Cadherin 23 & $\begin{array}{l}\text { Component of the tip link connecting hair cell } \\
\text { stereocilia }\end{array}$ & $\begin{array}{l}\text { USH1D, } \\
\text { DFNB12 }\end{array}$ & $22,24,27$ \\
\hline Ahl2 & & & & & 42 \\
\hline Ahl3 & & & & & 43 \\
\hline Ahl5 & Gipc3 & $\begin{array}{l}\text { GIPC PDZ domain-containing family, } \\
\text { member } 3\end{array}$ & $\begin{array}{l}\text { Scaffolding protein involved in hair cell } \\
\text { transduction }\end{array}$ & $\begin{array}{l}\text { DFNB15, } \\
\text { DFNB95 }\end{array}$ & 25 \\
\hline Ahl6 & & & & & 44 \\
\hline Ahl8 & Fscn2 & $\begin{array}{l}\text { Fascin homologue } 2 \text {, actin bundling } \\
\text { protein, retinal }\end{array}$ & Actin cross-linker in hair cell stereocilia & & 28,45 \\
\hline DRASIC & Asic3 & $\begin{array}{l}\text { Acid-sensing (proton-gated) ion } \\
\text { channel } 3\end{array}$ & Mechanoreceptor channel & & 48 \\
\hline Gpx1 & $G p \times 1$ & Glutathione peroxidase 1 & Anti-oxidant enzyme & & 49 \\
\hline $\mathrm{mt}-\mathrm{Tr}$ & $m t-T r$ & $\begin{array}{l}\text { Mitochondrially encoded tRNA } \\
\text { arginine }\end{array}$ & tRNA arginine of mitochondria & & 50 \\
\hline Pcdh15 & Pcdh15 & Protocadherin 15 & $\begin{array}{l}\text { Component of the tip link connecting hair cell } \\
\text { stereocilia }\end{array}$ & USH1F & 51 \\
\hline Pmca2 & Pmca2 & Plasma membrane calcium ATPase 2 & Calcium transporter & $\begin{array}{l}\text { Modifier of } \\
\text { DFNB12 }\end{array}$ & 52 \\
\hline
\end{tabular}

a Function in the auditory system, if known. ${ }^{\mathrm{b}}$ Any evidence that mutations in the gene cause hearing loss in humans.

loss of inner hair cells becomes evident at the base of the cochlear spiral. By 7 months of age, loss of spiral ganglion cells is also evident at the basal turn and is consistent with a secondary neuronal degeneration subsequent to inner hair cell loss [29]. Additionally, age-related changes are also seen in the spiral ligament and stria vascularis consisting of fibrocyte loss and thinning, respectively, although a direct causal link between these pathologies has yet to be determined [21]. Together, these pathological changes affect cochlear structures that match with the main ARHL subtypes proposed by Schuknecht (sensory,

The Mouse as a Model for Age-Related Hearing Loss neural and strial), the exception being that even with the broad cellular degeneration seen in these mice, they do not show a decline in endocochlear potential [21]. Furthermore, C57BL/6J mice have been employed to investigate the role of melanin pigment, expressed by the intermediate cells of the stria vascularis, as a protective factor against ARHL and noise-induced hearing loss. The study utilised two co-isogenic C57BL/6J substrains: C57BL/6J, which shows very little age-related endocochlear potential decline, and C57BL/6J-Tyr ${ }^{c-2 J}$, which does not produce any strial melanin due to a naturally 
occurring mutation in the tyrosinase locus. Assessment of these mice showed identical rates of hearing loss and sensory cell loss. However, when aged ( $>2$ years), the $\mathrm{C} 57 \mathrm{BL} / 6 \mathrm{~J}-\mathrm{Tyr}^{\mathrm{c}-2 J}$ mice have reduced endocochlear potentials compared to the pigmented C57BL/6J mice, and this correlates with a significantly reduced strial thickness in the albino mice due to a net loss of marginal cells [30]. The authors propose that absence of melanin may represent one of many genetic and environmental factors that promote age-related strial marginal cell loss perhaps through a reduced ability to scavenge reactive oxygen species (ROS), a known property of melanin. Anecdotally, while ethnic differences in hearing sensitivity are not well understood, African Americans have better puretone thresholds and a lower prevalence of hearing impairment than white or Hispanic Americans [2].

In addition to age-related sensory and strial changes in the inner ear, progressive loss of SGNs can lead to neural ARHL, and while commonly observed in humans and mice, little is known of the underlying processes. However, as with other forms of ARHL, the study of inbred and genetically engineered mutant lines is helping to address this. In particular, there are several mouse models that display sensorineural hearing loss caused by defects in mitochondrial function, e.g. Cs, Gpx1, mt-Tr, Polg1 and Sod1 (table 1). Indeed, mitochondrial pathology is associated with both inherited and acquired hearing loss. Inherited mitochondrial DNA (mtDNA) point mutations and deletions have been implicated in both syndromic and isolated sensorineural hearing loss, whereas a high frequency of acquired mtDNA mutations have been reported in patients with presbycusis [31, 32]. It has been hypothesised that mitochondrial dysfunction can occur as a result of oxidative stress, such that ROS produced by the mitochondria can damage critical mitochondrial components, including mtDNA and respiratory chain proteins [33]. Increased production of ROS with age likely leads to accumulation of mitochondrial damage, which in turn leads to energy depletion and eventually tissue dysfunction. Support for this comes from the study of aged mice lacking $\mathrm{Cu} / \mathrm{Zn}$ superoxide dismutase (Sod1), an anti-oxidant enzyme that protects cells from ROS, which display severe SGN degeneration [34]. Similarly, mice carrying an allele of the mitochondrial Polg DNA polymerase gene that causes mutations to accumulate in mtDNA also develop progressive hearing impairment due to apoptotic loss of SGNs [35]. At a systemic level, caloric restriction has been observed to delay ARHL in some strains (e.g. CBA/J) and to ameliorate agerelated SGN loss in $\mathrm{C} 57 \mathrm{BL} / 6 \mathrm{~J}$ mice. These effects are thought to occur through several pathways, influencing the insulin/IGF-1 pathway, increasing mitochondrial function and regulating gene expression, for example [36]. Interestingly, mice fed a diet rich in anti-oxidants that selectively improves the mitochondrial anti-oxidant defence system prevents SGN loss and delays ARHL [37].

Investigations of inbred strains and mouse models have greatly increased our knowledge regarding the genes and pathobiology associated with ARHL (table 1). These successes prove the utility of this model organism and support the continued use of the mouse for these studies. Ultimately, it is hoped that increased understanding of the underlying genetics will lead to therapeutic opportunities to ameliorate age-related auditory decline.

\section{Discovery of New Candidate ARHL Genes from Mouse Studies}

Recently, Ohmen et al. [38] reported the use of GWA studies for the high-resolution mapping of loci associated with ARHL in the mouse. By combining several heterogeneous phenotypic data sets in a meta-analysis, they successfully identified five loci showing genome-wide significance. One of these confirms the previously identified ahl8 locus, and the remaining four represent novel candidate loci for ARHL in mice. Interrogation of these and previously reported loci will lead to the identification of additional genes involved in age-related auditory function in inbred mouse strains.

As mentioned previously, phenotype-driven screens of chemically induced mouse mutants have been very effective for the identification of models of hearing loss. However, given the early-onset phenotyping bias inherent in many of these screens, the majority of identified mouse models have either congenital or acute early-onset phenotypes. Extending the approach to include screening of aged mutant mice would be one way to uncover new genes associated with age-related auditory function. However, the need to house and phenotype sufficient numbers of mice to an age to detect what are mild, late-onset phenotypes requires a major economic commitment. In addition, the presence of a pre-existing genetic susceptibility to ARHL in commonly used strains of laboratory mice is a confounding factor in the development of any ARHL screen. The MRC Harwell Ageing Screen is designed to address these issues and is the first large-scale project to successfully employ $\mathrm{N}$-ethyl-N-nitrosourea (ENU) mutagenesis and phenotyping to generate mouse models of age-related disease. Large reces- 
sive pedigrees are bred and enter a phenotyping pipeline comprising recurrent assessment across a wide range of disease areas, up to 18 months of age. The pipeline includes recurrent click box and auditory-evoked brainstem response phenotyping to enable the identification of models with ARHL [39]. Unlike standard screens, the large pedigrees utilised in this screen allow for genome mapping of the critical interval using only the original cohort of mice. As such, no breeding, ageing or phenotyping of additional animals is required for the identification of the causative ENU-induced mutation. To elaborate on the underlying lesion, whole genome sequencing followed by variant analysis is undertaken. This program is beginning to identify pedigrees with late-onset hearing loss phenotypes. It will be interesting to discover if these pedigrees harbour mutations in novel hearing loss genes, or if they have 'mild' alleles of known deafness genes.

\section{Validation and Characterisation of ARHL Genes in the Mouse}

The major genetic studies that have addressed adult hearing function in humans have identified candidate gene sets for ARHL susceptibility factors. However, the lack of genome-wide significant observations in these studies and lack of replication between different studies mean they will require secondary validation by other methods to distinguish the true ARHL susceptibility genes from chance observations. With the previously mentioned difficulties in performing any such functional characterisation in human tissue, the mouse is the most viable system in which to characterise the role of these genes in the auditory system. The most immediate way in which to validate their role in hearing is by examination of the hearing function in the relevant mutant mouse model; the Esrrg knock-out mouse was recently found to have a hearing deficit when investigated after a suggestive association with adult human hearing in a genome-wide study providing evidence for a link between this gene and hearing for the first time [13]. The aim of the International Mouse Phenotyping Consortium (https://www.mousephenotype.org/) to produce a functional knock-out mouse for every known gene will facilitate this process. Although its own primary phenotyping will detect early-onset hearing loss only, it will provide an opportunity for a systematic prioritisation of human GWA study genes by known hearing function in mice and an available model for further characterisation at an older age [40].

One of the most exciting recent developments in mouse research is the use of the CRISPR/Cas9 genome-editing technology, which provides a rapid and efficient way of generating mouse models [41]. In particular, this technique has the potential to enable the production of mouse mutants carrying specific gene mutations identified in patients, thus allowing disease-causing alleles to be modelled and characterised in the mouse. In the future, this approach will undoubtedly be used to test the pathogenicity of gene variants, including those identified through next-generation sequencing of families with progressive hearing loss. The facility to characterise a mouse model of a human mutation is of great benefit, as it will allow the primary site of pathology to be identified and the associated secondary pathobiological consequences to be monitored, something that is not possible in patients.

In conclusion, integrated human and mouse approaches will lead to a more profound understanding of the genetics underlying ARHL. The study and comparison of mouse models will provide essential information regarding the molecular and cellular processes occurring in the ageing mammalian cochlea. This increased understanding will lay the foundation necessary for developing preventive modalities, such as gene, anti-oxidant or stem cell therapies.

\section{References}

1 Stevens G, Flaxman S, Brunskill E, Mascarenhas M, Mathers CD, Finucane M; Global Burden of Disease Hearing Loss Expert Group: Global and regional hearing impairment prevalence: an analysis of 42 studies in 29 countries. Eur J Public Health 2013;23: 146-152.

2 Bainbridge KE, Wallhagen MI: Hearing loss in an aging American population: extent, impact, and management. Annu Rev Public Health 2014;35:139-152.
3 Gurgel RK, Ward PD, Schwartz S, Norton MC, Foster NL, Tschanz JT: Relationship of hearing loss and dementia: a prospective, population-based study. Otol Neurotol 2014; 35:775-781.

4 Li CM, Zhang X, Hoffman HJ, Cotch MF, Themann CL, Wilson MR: Hearing impairment associated with depression in US adults, National Health and Nutrition Examination Survey 2005-2010. JAMA Otolaryngol Head Neck Surg 2014;140:293-302.
5 Lin FR, Yaffe K, Xia J, Xue QL, Harris TB, Purchase-Helzner E, Satterfield S, Ayonayon HN, Ferrucci L, Simonsick EM; Health ABC Study Group: Hearing loss and cognitive decline in older adults. JAMA Intern Med 2013; 173:293-299.

6 Richardson GP, de Monvel JB, Petit C: How the genetics of deafness illuminates auditory physiology. Annu Rev Physiol 2011;73:311-334.

7 Schuknecht HF: Presbycusis. Laryngoscope 1955;65:402-419.
The Mouse as a Model for Age-Related Hearing Loss 
8 Schuknecht HF, Gacek MR: Cochlear pathology in presbycusis. Ann Otol Rhinol Laryngol 1993;102:1-16.

-9 Ohlemiller KK: Age-related hearing loss: the status of Schuknecht's typology. Curr Opin Otolaryngol Head Neck Surg 2004;12:439443.

10 Friedman RA, Van Laer L, Huentelman MJ, Sheth SS, Van Eyken E, Corneveaux JJ, Tembe WD, Halperin RF, Thorburn AQ, Thys S, Bonneux S, Fransen E, Huyghe J, Pyykko I, Cremers CW, Kremer H, Dhooge I, Stephens D, Orzan E, Pfister M, Bille M, Parving A, Sorri M, Van de Heyning PH, Makmura L, Ohmen JD, Linthicum FH Jr, Fayad JN, Pearson JV, Craig DW, Stephan DA, Van Camp G: GRM7 variants confer susceptibility to age-related hearing impairment. Hum Mol Genet 2009;18:785-796.

-11 Van Laer L, Huyghe JR, Hannula S, Van Eyken E, Stephan DA, Maki-Torkko E, Aikio P, Fransen E, Lysholm-Bernacchi A, Sorri M, Huentelman MJ, Van Camp G: A genomewide association study for age-related hearing impairment in the Saami. Eur J Hum Genet 2010;18:685-693.

-12 Girotto G, Pirastu N, Sorice R, Biino G, Campbell H, d'Adamo AP, Hastie ND, Nutile T, Polasek O, Portas L, Rudan I, Ulivi S, Zemunik T, Wright AF, Ciullo M, Hayward C, Pirastu M, Gasparini P: Hearing function and thresholds: a genome-wide association study in European isolated populations identifies new loci and pathways. J Med Genet 2011;48: 369-374.

13 Nolan LS, Maier H, Hermans-Borgmeyer I, Girotto G, Ecob R, Pirastu N, Cadge BA, Hubner C, Gasparini P, Strachan DP, Davis A, Dawson SJ: Estrogen-related receptor gamma and hearing function: evidence of a role in humans and mice. Neurobiol Aging 2013;34: 2077.e1-e9.

14 Fransen E, Bonneux S, Corneveaux JJ, Schrauwen I, Di Berardino F, White CH, Ohmen JD, Van de Heyning P, Ambrosetti U, Huentelman MJ, Van Camp G, Friedman RA: Genome-wide association analysis demonstrates the highly polygenic character of age-related hearing impairment. Eur J Hum Genet 2014, Epub ahead of print.

15 Brown SD, Hardisty-Hughes RE, Mburu P: Quiet as a mouse: dissecting the molecular and genetic basis of hearing. Nat Rev Genet 2008;9:277-290.

-16 Friedman LM, Dror AA, Avraham KB: Mouse models to study inner ear development and hereditary hearing loss. Int J Dev Biol 2007; 51:609-631.

17 Petit C: From deafness genes to hearing mechanisms: harmony and counterpoint. Trends Mol Med 2006;12:57-64.

18 Schwander M, Sczaniecka A, Grillet N, Bailey JS, Avenarius M, Najmabadi H, Steffy BM, Federe GC, Lagler EA, Banan R, Hice R, Grabowski-Boase L, Keithley EM, Ryan AF, Housley GD, Wiltshire T, Smith RJ, Tarantino LM, Muller U: A forward genetics screen in mice identifies recessive deafness traits and reveals that pejvakin is essential for outer hair cell function. J Neurosci 2007;27 2163-2175

19 Acevedo-Arozena A, Wells S, Potter P, Kelly $\mathrm{M}$, Cox RD, Brown SD: ENU mutagenesis, a way forward to understand gene function. Annu Rev Genomics Hum Genet 2008;9:4969.

20 Vanhooren V, Libert C: The mouse as a model organism in aging research: usefulness, pitfalls and possibilities. Ageing Res Rev 2013; 12:8-21.

21 Ohlemiller KK: Contributions of mouse models to understanding of age- and noise-related hearing loss. Brain Res 2006;1091:89-102.

22 Johnson KR, Zheng QY, Erway LC: A major gene affecting age-related hearing loss is common to at least ten inbred strains of mice. Genomics 2000;70:171-180.

23 Davis RR, Kozel P, Erway LC: Genetic influences in individual susceptibility to noise: a review. Noise Health 2003;5:19-28.

24 Erway LC, Shiau YW, Davis RR, Krieg EF: Genetics of age-related hearing loss in mice. III. Susceptibility of inbred and F1 hybrid strains to noise-induced hearing loss. Hear Res 1996; 93:181-187.

25 Charizopoulou N, Lelli A, Schraders M, Ray K, Hildebrand MS, Ramesh A, Srisailapathy CR, Oostrik J, Admiraal RJ, Neely HR, Latoche JR, Smith RJ, Northup JK, Kremer H, Holt JR, Noben-Trauth K: Gipc3 mutations associated with audiogenic seizures and sensorineural hearing loss in mouse and human. Nat Commun 2011;2:201.

26 Johnson KR, Gagnon LH, Longo-Guess C, Kane KL: Association of a citrate synthase missense mutation with age-related hearing loss in A/J mice. Neurobiol Aging 2012;33: 1720-1729.

27 Noben-Trauth K, Zheng QY, Johnson KR: Association of cadherin 23 with polygenic inheritance and genetic modification of sensorineural hearing loss. Nat Genet 2003;35:2123.

28 Shin JB, Longo-Guess CM, Gagnon LH, Saylor KW, Dumont RA, Spinelli KJ, Pagana JM, Wilmarth PA, David LL, Gillespie PG, Johnson KR: The R109H variant of fascin-2, a developmentally regulated actin crosslinker in hair-cell stereocilia, underlies early-onset hearing loss of DBA/2J mice. J Neurosci 2010; 30:9683-9694.

29 Hequembourg S, Liberman MC: Spiral ligament pathology: a major aspect of age-related cochlear degeneration in C57BL/6 mice. J Assoc Res Otolaryngol 2001;2:118-129.

30 Ohlemiller KK, Rice ME, Lett JM, Gagnon PM: Absence of strial melanin coincides with age-associated marginal cell loss and endocochlear potential decline. Hear Res 2009;249: $1-14$.

31 Fischel-Ghodsian N, Bykhovskaya Y, Taylor K, Kahen T, Cantor R, Ehrenman K, Smith R, Keithley E: Temporal bone analysis of patients with presbycusis reveals high frequency of mitochondrial mutations. Hear Res 1997; 110:147-154

32 Fischel-Ghodsian N, Kopke RD, Ge X: Mitochondrial dysfunction in hearing loss. Mitochondrion 2004;4:675-694.

33 Han C, Someya S: Mouse models of age-related mitochondrial neurosensory hearing loss. Mold Cell Neurosci 2013;55:95-100.

-34 McFadden SL, Ding D, Reaume AG, Flood DG, Salvi RJ: Age-related cochlear hair cell loss is enhanced in mice lacking copper/zinc superoxide dismutase. Neurobiol Aging 1999; 20:1-8.

35 Someya S, Yamasoba T, Kujoth GC, Pugh TD, Weindruch R, Tanokura M, Prolla TA: The role of mtDNA mutations in the pathogenesis of age-related hearing loss in mice carrying a mutator DNA polymerase gamma. Neurobiol Aging 2008;29:1080-1092.

36 Bao J, Ohlemiller KK: Age-related loss of spiral ganglion neurons. Hear Res 2010;264:9397.

-37 Someya S, Prolla TA: Mitochondrial oxidative damage and apoptosis in age-related hearing loss. Mech Ageing Dev 2010;131: 480-486.

38 Ohmen J, Kang EY, Li X, Joo JW, Hormozdiari F, Zheng QY, Davis RC, Lusis AJ, Eskin E, Friedman RA: Genome-wide association study for age-related hearing loss (AHL) in the mouse: a meta-analysis. J Assoc Res Otolaryngol 2014;15:335-352.

39 Hardisty-Hughes RE, Parker A, Brown SD: A hearing and vestibular phenotyping pipeline to identify mouse mutants with hearing impairment. Nat Protoc 2010;5:177-190.

40 Brown SD, Moore MW: The international mouse phenotyping consortium: past and future perspectives on mouse phenotyping. Mamm Genome 2012;23:632-640.

41 Wang H, Yang H, Shivalila CS, Dawlaty MM, Cheng AW, Zhang F, Jaenisch R: One-step generation of mice carrying mutations in multiple genes by CRISPR/Cas-mediated genome engineering. Cell 2013;153:910-918.

42 Johnson KR, Zheng QY: Ahl2, a second locus affecting age-related hearing loss in mice. Genomics 2002;80:461-464.

43 Nemoto M, Morita Y, Mishima Y, Takahashi S, Nomura T, Ushiki T, Shiroishi T, Kikkawa Y, Yonekawa H, Kominami R: Ahl3, a third locus on mouse chromosome 17 affecting age-related hearing loss. Biochem Biophys Res Commun 2004;324:1283-1288.

44 Drayton M, Noben-Trauth K: Mapping quantitative trait loci for hearing loss in Black Swiss mice. Hear Res 2006;212:128-139.

-45 Johnson KR, Longo-Guess C, Gagnon LH, Yu $\mathrm{H}$, Zheng QY: A locus on distal chromosome 11 (ahl8) and its interaction with Cdh23 ahl underlie the early onset, age-related hearing loss of DBA/2 J mice. Genomics 2008;92:219225.

46 Guo Y, Zhang C, Du X, Nair U, Yoo TJ: Morphological and functional alterations of the cochlea in apolipoprotein $\mathrm{E}$ gene deficient mice. Hear Res 2005;208:54-67. 
47 Bao J, Lei D, Du Y, Ohlemiller KK, Beaudet AL, Role LW: Requirement of nicotinic acetylcholine receptor subunit beta2 in the maintenance of spiral ganglion neurons during aging. J Neurosci 2005;25:30413045.

48 Hildebrand MS, de Silva MG, Klockars T, Rose E, Price M, Smith RJ, McGuirt WT, Christopoulos H, Petit C, Dahl HH: Characterisation of DRASIC in the mouse inner ear. Hear Res 2004;190:149-160.

49 Ohlemiller KK, McFadden SL, Ding DL, Lear PM, Ho YS: Targeted mutation of the gene for cellular glutathione peroxidase (Gpx1) increases noise-induced hearing loss in mice. J Assoc Res Otolaryngol 2000;1:243-254.
50 Johnson KR, Zheng QY, Bykhovskaya Y, Spirina $\mathrm{O}$, Fischel-Ghodsian N: A nuclear-mitochondrial DNA interaction affecting hearing impairment in mice. Nat Genet 2001;27:191194.

51 Zheng QY, Yan D, Ouyang XM, Du LL, Yu H, Chang B, Johnson KR, Liu XZ: Digenic inheritance of deafness caused by mutations in genes encoding cadherin 23 and protocadherin 15 in mice and humans. Hum Mol Genet 2005; 14:103-111.

52 Kozel PJ, Davis RR, Krieg EF, Shull GE, Erway LC: Deficiency in plasma membrane calcium ATPase isoform 2 increases susceptibility to noise-induced hearing loss in mice. Hear Res 2002;164:231-239.
53 Minowa O, Ikeda K, Sugitani Y, Oshima T, Nakai S, Katori Y, Suzuki M, Furukawa M, Kawase T, Zheng Y, Ogura M, Asada Y, Watanabe $\mathrm{K}$, Yamanaka $\mathrm{H}$, Gotoh S, NishiTakeshima M, Sugimoto T, Kikuchi T, Takasaka T, Noda T: Altered cochlear fibrocytes in a mouse model of DFN3 nonsyndromic deafness. Science 1999;285:1408-1411.

54 Xia AP, Kikuchi T, Minowa O, Katori Y, Oshima T, Noda T, Ikeda K: Late-onset hearing loss in a mouse model of DFN3 non-syndromic deafness: morphologic and immunohistochemical analyses. Hear Res 2002;166:150-158.

55 Tabuchi K, Suzuki M, Mizuno A, Hara A Hearing impairment in TRPV4 knockout mice. Neurosci Lett 2005;382:304-308. 